\title{
ESPAÇOS LIVRES PÚBLICOS E ÁREAS INSTITUCIONAIS COM USOS ALTERADOS - MICRORREGIÃO 08 DE PRESIDENTE PRUDENTE - SP
}

\author{
Anderson de Oliveira Ferreira Lima, Bruno Rafael Fernandes, Lívia de Oliveira Ferreira e Silva, \\ Marcos Norberto Boin, Yeda Ruiz Maria \\ Universidade do Oeste Paulista - UNOESTE. Curso de Arquitetura e Urbanismo, Presidente Prudente - SP. E-mail: \\ yedarm@hotmail.com
}

\section{RESUMO}

Com o acelerado processo de urbanização e o constante crescimento das cidades, os espaços livres públicos tornaram-se mais necessários e de vital importância, agregando qualidades ao ambiente urbano através das condições ambientais, de funcionalidade e sociabilidade, além do caráter estético atribuído aos lugares. Contudo, como este processo normalmente acontece de forma não planejada, as cidades brasileiras têm dificuldade na implantação de áreas urbanas para formar um sistema de espaços livres públicos coeso e completo, que atenda de maneira ampla e coerente toda a cidade. Assim sendo, a presente pesquisa propõe o estudo das áreas públicas da microrregião 08 do município de Presidente Prudente - SP, verificando sua real utilização na atualidade, visto que, nos parcelamentos do solo da cidade, seus espaços públicos e áreas institucionais foram concedidos a terceiros, reduzindo as possibilidades do poder público municipal em atender as necessidades de instalação dos equipamentos urbanos e comunitários para a população prudentina.

Palavras-chave: Espaço livre público. Área de lazer. Área institucional. Microrregião 08. Presidente Prudente - SP.

\section{PUBLIC SPACES AND INSTITUTIONAL AREAS WITH ALTERED USES - MICROREGION 08 OF PRESIDENTE PRUDENTE - SP}

\begin{abstract}
With the accelerated process of urbanization and the constant growth of cities, public open spaces have become more necessary and vital, adding qualities to the urban environment by environmental conditions, functionality and sociability, beyond the aesthetic character attributed to places. However, as this process usually happens in an unplanned manner, Brazilian cities have difficulty in the implementation of urban areas to form a cohesive system of free and full public spaces, which meets a broad and coherent manner across the city. Therefore, this research proposes the study of the public areas of the 08 micro municipality of Presidente Prudente - SP, checking their actual use today, since the installment of the soil of the city, its public spaces and institutional areas were granted to third parties reducing the possibilities of municipal government in addressing the needs of installation of urban equipment and community for the city's population.

Keywords: Free public space. Recreation area. Institutional area. Microregion 08 Presidente Prudente - SP.
\end{abstract}




\section{INTRODUÇÃO E JUSTIFICATIVA}

O modo de apropriação particular das questões sociais, econômicas e ambientais em paralelo com a urbanização acelerada e a falta de políticas públicas que direcionem o panorama das mesmas ao longo do tempo, tem provocado o surgimento e crescimento de cidades sem planejamento (PINHEIRO, 2010).

Com a Lei de Parcelamento do Solo Urbano (Lei n. 6.766/1979), criada para suprir as necessidades de controle do uso, ocupação e parcelamento dos loteamentos, observa-se uma nova problemática originada justamente pela atribuição do rígido controle desses usos e ocupações por parte dos próprios municípios. Entretanto, de início, essas novas normas não eram respaldadas, por instituições e/ou órgãos competentes da gestão do território urbano.

Nesta vertente tem-se o artigo 22 da referida lei, no qual institui que os espaços destinados à implantação de "vias e praças, os espaços livres e as áreas destinadas a edifícios públicos e outros equipamentos urbanos", assim como as áreas do sistema de circulação, após o registro em cartório do loteamento, passam a integrar os bens de domínio público do município, tornando-se inalienáveis e imprescritíveis por natureza, por serem também regulados pelo regime jurídico administrativo (Código Civil Brasileiro, art. 99, I e art. 100). Consta ainda na Lei de Parcelamento que, todo loteamento urbano, para ser aprovado perante a Prefeitura, precisa reservar parte do imóvel, em percentual definido em lei municipal, para construção de praças, escolas, postos de saúde e outros equipamentos comunitários necessários ao atendimento dos futuros moradores daquele empreendimento, tendo-se assim as áreas definidas como de lazer e institucionais.

O Estatuto da Cidade (Lei n.10.257/2001), em seu objetivo principal, estabelece normas de ordem pública e interesse social que regulam o uso da propriedade urbana em prol do bem coletivo, da segurança e do bem-estar dos cidadãos, bem como do equilíbrio ambiental, sendo estas áreas reservadas nos loteamentos para uso comum da população também protegidas pela Constituição Estadual Paulista (1989), que não permite a alteração do uso do solo, salvo raras exceções que constam nas emendas sancionadas nos anos de 2007 e 2008, mediante compensação para situações de regularização e de interesse social.

Partindo do pressuposto que o espaço público é o conjunto de diferentes usos da terra que se correlacionam entre si, se percebe o complexo sistema que engloba o contexto do conceito. Assim sendo o espaço livre - uma das variantes do termo - é qualquer espaço urbano fora das edificações e ao ar livre, de caráter aberto e destinado ao pedestre e ao público no geral, independente de seu uso. Este conjunto de espaços urbanos - edificados e livres - é conceituado por Sá Carneiro e Mesquita (2000) como resultante de ações humanas, por Del Rio (1990) como 
palco das "atividades sociais", podendo ainda exercer importante papel na identidade dos lugares (Pizzol, 2005).

O mesmo ocorre com o termo áreas verdes que, segundo Cavalheiro e Del Picchia (1992, p. 30-31), estariam mais adequadamente representadas se fossem intituladas ou inseridas na categoria de "espaços livres", juntamente com as áreas institucionais. Ainda como citam Benini e Martin (2010, p. 77), área verde pública é:

Todo espaço livre (área verde/lazer) que foi afetado como de uso comum e que apresente algum tipo de vegetação (espontânea ou plantada), que possa contribuir em termos ambientais [...] e que também seja utilizado com objetivos sociais, ecológicos, científicos ou culturais.

Atualmente os espaços livres públicos se tornaram mais necessários e de vital importância, agregando qualidades ao ambiente urbano através das condições de funcionalidade, sociabilidade, ambientais e sanitárias, além do caráter estético atribuído aos lugares (CUNHA, 2003). Entretanto as cidades têm dificuldade na implantação de áreas urbanas para formar um sistema de espaços livres públicos coeso e completo, que atenda de maneira ampla e coerente toda a cidade (MENNHE e COELHO, 1999).

Assim sendo, a presente pesquisa propõe o estudo das áreas públicas da microrregião 08 do município de Presidente Prudente - SP (aprovados a partir de 1980, após a promulgação da Lei Federal no 6.766/1979), verificando sua real utilização na atualidade, tendo como referência-base os processos do Ministério Público Estadual e as informações oficiais disponibilizadas pela Prefeitura Municipal da cidade.

A metodologia teve como base levantamento bibliográfico para base conceitual sobre os termos "áreas livres públicas" e "áreas institucionais". Em seguida, com a pesquisa documental houve contato com políticas e ações voltadas às áreas livres públicas e institucionais, legislação municipal, estadual e federal relacionadas ao parcelamento, uso e ocupação do solo urbano, mapeamentos de aspectos como estrutura urbana municipal, localização e mapeamento dos bairros constituintes da microrregião 08 e uso atual dessas áreas. Para tanto, foram levantadas plantas dos loteamentos, leis e decretos disponíveis na página oficial da Prefeitura Municipal da cidade, obtidos por meio da internet, e o Inquérito Civil n. 323/11-6 do Ministério Público do Estado de São Paulo aberto para averiguar o assunto.

Utilizando-se de técnicas de geoprocessamento e sensoriamento remoto, através do Programa Spring 5.2.3, sobre imagem de fotografias aéreas e imagem de satélite do Google Earth (Digital Globe), mapearam-se as áreas da referida microrregião para então se verificar a situação 
das áreas públicas existentes nas plantas dos loteamentos obtidas por meio do website oficial da Prefeitura Municipal.

Após o levantamento da situação das áreas públicas dos loteamentos da microrregião, efetuado através de visitas in loco para a verificação da real destinação dada às mesmas, a continuidade da pesquisa está sendo organizada em inventário e elaboração de diagnóstico urbanístico.

\section{PRESIDENTE PRUDENTE E A MICRORREGIÃO 08 - BREVE ANÁLISE}

A cidade de Presidente Prudente, localizada no extremo oeste paulista - região denominada Alta Sorocabana - foi fundada no dia 14 de setembro de 1917 e, segundo o senso do IBGE (2010), abriga atualmente uma população de 203.375 habitantes.

A expansão da cidade, que atualmente é constituída por 19 microrregiões - além de seu Zoneamento Urbano -, é apontada por Honda (2010) como uma cidade que teve sua dinâmica direcionada para sudoeste, deixando grandes vazios urbanos, tendo provocado regularização de loteamentos, lotes e, inclusive, de áreas devolutas.

Entretanto, os vazios existentes no interior da malha urbana não atendem as necessidades da municipalidade para a instalação dos equipamentos urbanos, pelo contrário, vêm agravar a expansão desordenada da cidade exigindo, além de outros fatores, uma infraestrutura ampliada e onerosa.

Nos parcelamentos de solo existentes antes e após a Lei de Parcelamento, as áreas/espaços públicos (verdes e institucionais) de Presidente Prudente, foram concedidas e doadas a terceiros, reduzindo assim as possibilidades do poder público municipal em atender as necessidades de instalação dos equipamentos urbanos e comunitários para a população prudentina.

O artigo 12 do Plano Diretor (1996) da cidade estabelece que os loteamentos "deverão" atender certas relações de proporcionalidade e características do município, bem como a constituição das áreas públicas por: áreas institucionais, sistema viário, áreas de preservação ambiental e/ou non aedificandi, quando for o caso.

Com base nestes conceitos apresentados e no que a lei institui, a nível federal, estadual e municipal, busca-se, por meio desta pesquisa, realizar um levantamento de usos dos espaços livres públicos e áreas institucionais de Presidente Prudente - SP, mais especificamente dos bairros que compõem a microrregião 08 (figura 01): Bosque Itajú, Chácara do Macuco I, Chácara do Macuco II, Jardim Alto da Boa Vista, Jardim Rio 400, Jardim Satélite, Parque Higienópolis, Parque Residencial Nosaki, Residencial Damha, Residencial Damha II, Residencial Damha III, Residencial Florenza, 
Residencial Golden Vilage, Residencial Quinta das Flores, Residencial Século XXI, Taba Tori, Vilage Damha, Vila Maria, Vila Nova Prudente e alguns outros bairros sem denominação oficial.

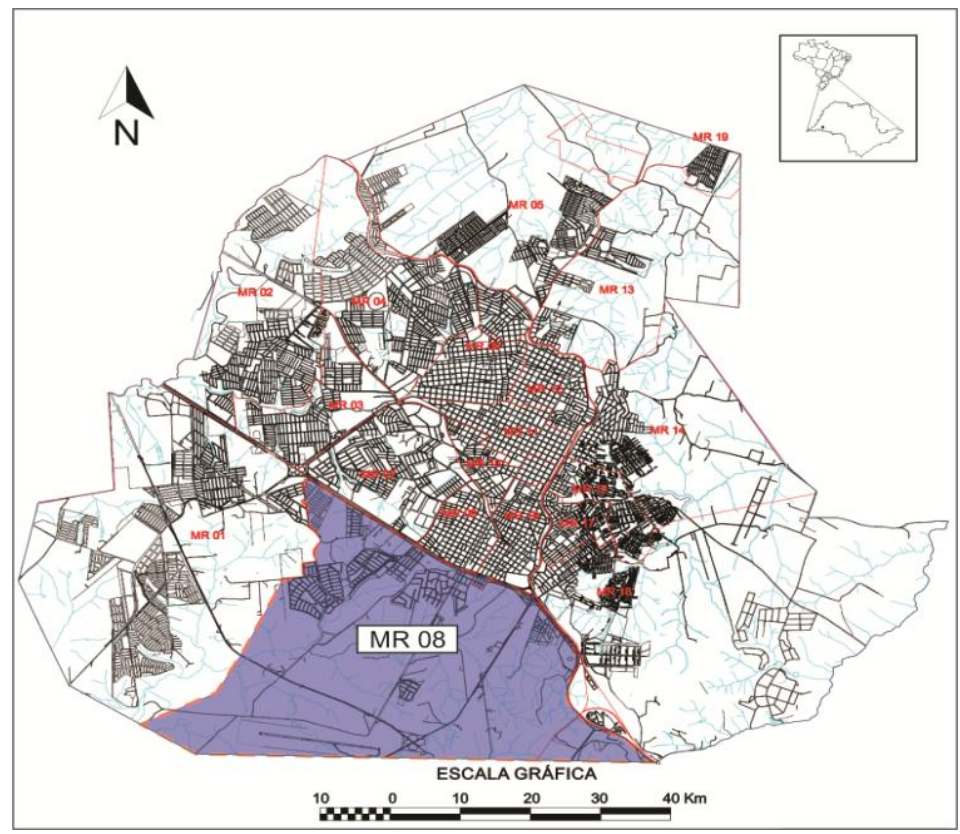

FIGURA 1. Localização da cidade de Presidente Prudente e a Microrregião-08 Fonte: Autores, 2014

Na referida microrregião, os bairros começaram a ser instalados na década de 1970, porém, a grande maioria, a partir dos anos 90, o que lhes é conferido a tutela das áreas públicas à Lei de Parcelamento do Solo, promulgada em 1979. Nestes bairros de diferentes padrões de vida, os espaços públicos foram drasticamente reduzidos em número e em área, o que implica a necessidade atual de aquisição de áreas para estes fins por parte do poder público, o que é agravado pela deficiência em equipamentos urbanos - especialmente nos bairros que abrigam a população de menor poder aquisitivo.

\section{MICRORREGIÃO 08 - ESTUDO DE CASO}

A microrregião 08 localiza-se ao sul da malha urbana e compreende a maior área da cidade com território murado - os condomínios fechados Residenciais Damha, Damha II, Damha III, Vilage Damha, Golden Vilage e Quinta das Flores -, os quais apresentam inadequadamente áreas destinadas ao lazer dentro do território, haja vista que essas áreas deveriam estar isentas de cercamento, garantindo assim o acesso por parte do público em geral, respaldado pela Lei de Parcelamento e Estatuto da Cidade.

Vale destacar que as áreas institucionais dos mesmos encontram-se todas sem uso. Como exemplo de irregularidades tem-se a do Residencial Damha que é utilizada como sistema viário, 
sendo também o principal acesso ao Residencial Damha II, o qual tem seu setor institucional sobre uma Área de Preservação Permanente - APP. ${ }^{1}$ Já o condomínio fechado Vilage Damha não apresenta área institucional.

A Chácara do Macuco I é um bairro inteiramente murado. Suas áreas de lazer e institucional não são edificadas, entretanto são terrenos utilizados atualmente para a pastagem de animais, com acesso apenas pela Chácara do Macuco II.

Os bairros Higienópolis e Rio 400 são habitados exclusivamente por população de classe abastada. Ambos possuem áreas de lazer de significativas proporções e em bom estado, entretanto, em suas áreas institucionais estão presentes edificações para outros fins que não de recreação.

O Bosque Itajú tem sua área institucional ocupada por residências particulares, seu espaço de lazer (parquinho) sofre com a falta de manutenção da vegetação.

O Jardim Alto da Boa Vista apresenta suas áreas de lazer separadas em duas quadras centrais. A primeira ocupada irregularmente por uma sede dos Correios (institucional) e a segunda possui um campo de futebol, parque e academia. Já a área institucional encontra-se, em parte, ocupada regularmente por edificação destinada à entidade sem fins lucrativos, sendo que o outro lote está desocupado.

O Residencial Florenza é relativamente bem arborizado e recortado em sua região norte por uma APP identificada como faixa non aedificandi, tendo sido adicionada a esta, uma pequena área verde do bairro. Possui ainda áreas de lazer bem demarcadas, porém, com vegetação arbórea sem manutenção, utilização dos espaços como depósito de lixo e/ou inadequadamente apropriados para fins particulares dos moradores. Os espaços institucionais abrigam a implantação inadequada e irregular de equipamentos de lazer.

O Parque Residencial Nosaki tem suas áreas públicas implantadas em quadras concentradas, onde estão instalados uma academia, parque e campo de futebol. Sua área institucional é desprovida de qualquer tipo de edificação, apresentando vegetação sem manutenção. O Jardim Satélite possui em sua área uma parte destinada ao uso institucional e outra de maior tamanho para lazer, porém as mesmas estão ocupadas irregularmente com grande edificação destinada à instituição sem fins lucrativos.

Os bairros Vila Maria e Vila Nova Prudente não possuem clara delimitação que diferencie

\footnotetext{
${ }^{1}$ (Lei n. 12.651, de 25 de maio de 2012. Art. $3^{\circ}$ - Para os efeitos desta Lei, entende-se por: “[...] II - Área de Preservação Permanente - APP: área protegida, coberta ou não por vegetação nativa, com a função ambiental de preservar os recursos hídricos, a paisagem, a estabilidade geológica e a biodiversidade, facilitar o fluxo gênico de fauna e flora, proteger o solo e assegurar o bem-estar das populações humanas".

A área em questão por ser de importância ambiental, tendo sua preservação protegida por lei, não pode ser edificada.
} 
seus limites. São, no geral, habitados por população de classe baixa, apresentando irregularidades tanto em suas moradias quanto nas pequenas áreas livres - estando estas últimas em não conformidade com as porcentagens estabelecidas pelas normas municipais de parcelamento. Todavia, os usos aos quais foram destinadas as mesmas, obtidas por meio de desapropriação por parte da municipalidade, podem ser considerados adequados.

O Residencial Século XXI, o Taba Tori e a Chácara do Macuco II são loteamentos ainda não consolidados, apresentando ainda certa marcação do traçado viário, porém sem asfaltamento e com início de infraestrutura básica encontrada em situações precárias e não finalizada. Na análise da situação atual não é possível observar com clareza a delimitação de suas áreas públicas, no entanto, sabe-se que, a partir das plantas de loteamento são áreas não ocupadas.

\section{CONCLUSÃO}

Assim sendo, pode-se inferir que o problema da alteração de uso dos espaços livres públicos e institucionais da cidade de Presidente Prudente está, em sua maioria, intimamente ligado a interesses particulares - públicos e privados - beneficiando uma minoria privilegiada em detrimento dos direitos da coletividade. Do ponto de vista urbanístico, têm-se algumas das medidas a serem tomadas para a gradativa mudança desse panorama, fortalecendo assim a maior aplicação dos benefícios concedidos por lei. Os equipamentos a serem implantados nos espaços livres públicos - praças, parques, equipamentos institucionais (escolas, creches, postos de saúde, etc.) - devem se tornar obrigatórios desde o início e entrega do loteamento, como é o caso da rede de infraestrutura básica - água, esgoto, eletricidade, etc. -, bem como o estímulo às propostas em nível do contexto geral da cidade e suas particularidades. Os lotes vazios e/ou áreas circunvizinhas sem uso no território dos bairros e loteamentos que possuem irregularidades devem ser cedidos e ocupados, através de meios legais, com o objetivo de compensar essas áreas em situação inadequada (muitas vezes em casos irreversíveis), para a implantação de dispositivos públicos de lazer e institucionais, buscando suprir as necessidades e o melhor atendimento da população da cidade. Vale ressaltar a continuidade da pesquisa que consiste ainda na organização de inventário e elaboração de diagnóstico urbanístico mais completo e detalhado.

\section{REFERÊNCIAS}

BRASIL. Lei n. 6.766, de 19 de dezembro de 1979. Dispõe sobre o Parcelamento do Solo Urbano e dá outras providências. Alterada pela Lei no 9.785, de 29 de Janeiro de 1999.

BRASIL. Lei n. 10.257, de 10 de julho de 2001. Estatuto da Cidade. Regulamenta os arts. 182 e 183 
da Constituição Federal, estabelece diretrizes gerais da política urbana e dá outras providências.

BRASIL. Lei n. 12.651, de 25 de maio de 2012. Dispõe sobre a proteção da vegetação nativa e dá outras providências.

BENINI, S. M.; MARTIN E. S. Decifrando as Áreas Verdes Públicas. In: Revista Formação, n.17, volume 2 - p. 63-80. UNESP/Presidente Prudente 2010.

CAVALHEIRO, Felisberto; DEL PICCHIA, P. C. D. Áreas verdes: conceitos, objetivos e diretrizes para o planejamento. In: Encontro Nacional Sobre Arborização Urbana. Vitória-ES, de 13 a 18 de set/1992, Anais I e II, pp.29-38, 1992. Disponível em: <http://www.geografia.ufpr.br/laboratorios/labs/arquivos/CAVALHEIRO\%20et\%20al\%20(1992).pdf >. Acesso em: 21 jul. 2014.

CAVALHEIRO, F. et al. Proposição de terminologia para o verde urbano. Boletim Informativo Sociedade Brasileira de Arborização Urbana, RJ: SBAU, ano VII, n.3, p.7, jul./ago./set. 1999. Disponível em: <http://www.geografia.ufpr.br/laboratorios/labs/ arquivos/CAVALHEIRO\%20et\%20al\%20(1999).pdf> Acesso em: 21 jul. 2014.

CUNHA, R.D.A. Os espaços públicos abertos e as leis de uso e ocupação do solo: uma questão de qualidade para ambientes sustentáveis. III Enecs - Encontro Nacional sobre Edificações e Comunidades Sustentáveis. 2003.

DEL RIO, V. Introdução ao desenho urbano no processo de planejamento. São Paulo, PINI, 1990. HONDA, S. C. A L. Habitação de baixa renda como produto do capital: 0 programa de arrendamento residencial (PAR) em Presidente Prudente - SP. Tese de Doutorado. Universidade Presbiteriana Mackenzie. São Paulo. 2010. 203p.

MENNHE, M.H.; COELHO, A.M. Características do sistema de parques públicos urbanos da cidade de São Paulo. In: ENTAC, 8, 2000, Salvador. ANAIS, Salvador: ANTAC., 2000. 8 p. CD-ROM. Seção artigos.

NUCCl, J.C. Qualidade ambiental e adensamento urbano: um estudo de ecologia e planejamento da paisagem aplicado ao distrito de Santa Cecília (MSP). 2a ed. Curitiba: O Autor, 2008. 150 p.

PIZZOL, K.M.S. de A. Uso e apropriação dos espaços livres públicos e informais de uma área urbana em João Pessoa- PB. 174 f. Dissertação de Mestrado (Meio Ambiente e espaços livres)Programa PRODEMA, UFPB/ João Pessoa, 2005.

PINHEIRO, O. M.; Plano Diretor e Gestão Urbana. Florianópolis Departamento de Ciências da Administração. UFSC, 2010.

SÃO PAULO. Constituição (1989). Constituição do Estado de São Paulo. Diário Oficial do estado de São Paulo, São Paulo, 6 out. 1989. 